\title{
Ankle taping: Support given by different materials
}

\author{
G. Capasso, MD ${ }^{1}$, N. Maffulli, MD ${ }^{1,2}$, V. Testa, $M^{1}$
}

'First Institute of Orthopaedics and Traumatology, University of Naples, Italy

${ }^{2}$ Sports Medicine Laboratory, Respiratory and Anaesthetic Unit, Institute of Child Health, London

\begin{abstract}
Three different adhesive and two non-adhesive tapes were used by the three operators to assess the compressive action exerted on the ankle at the moment of strapping, during different phases of gait, and after some days of treatment in ten volunteers.

Only the adhesive tapes were still able to prevent swelling after five days. They should be used if a prolonged compressive action is required.
\end{abstract}

Keywords: Ankle sprains, strapping, sports medicine, sports injuries

\section{Introduction}

Inversion injuries of the ankle are common among sportsmen ${ }^{1,2}$. Taping is widely and routinely used to support the ankle joint when injured ${ }^{3}$ and to prevent injury in normal ankles ${ }^{2-5}$, or further re-injury ${ }^{6}$. It significantly decreases instability after even violent physical activity ${ }^{7}$. Taping is a fundamental component of the RICE (Rest-Ice-Compression-Elevation) treatment programme ${ }^{8}$. The compression exerted varies with the material, technique and operator ${ }^{2,9}$. A properly strapped ankle can withstand torque forces up to $420 \mathrm{Nm}^{\text {? }}$.

The present investigation compares the compressive support given by different tapes when applied by different operators. Non-adhesive tapes have been chosen because they are cheap and easy to handle even by non-specialised personnel. The Thuasne tape is re-usable.

\section{Materials and methods}

Three experienced operators participated in this study. Ten volunteers (age $25 \pm 4.2$ years, range $19-31$ years; weight $64 \pm 7.3 \mathrm{~kg}$, range $58-82 \mathrm{~kg}$ ) gave their consent to take part. Five tapes were used:

1 Transelast (Lohman): non-adhesive elastic

2 Thuasne (Thuasne): cohesive elastic

3 Porelast (Lohman): elastic adhesive

4 Tensoplast (Smith \& Nephew): elastic adhesive

5 Elastikon (Johnson \& Johnson): elastic adhesive.

Each of the ten subjects underwent ankle taping with the five different tapes by the three different operators in a random order. A standard technique was used ${ }^{9,11}$. Both ankles were strapped at the same

Address for correspondence: Dr N. Maffulli, Institute of Child Health, Respiratory and Anaesthetic Unit, Sports Medicine Laboratory, 30 Guilford Street, London WC1

(C) 1989 Butterworth \& Co (Publishers) Ltd 0306-3674/89/040239-02 \$03.00 time, each by a different operator and with a different tape.

The compressive power exerted by the tapes was assessed by wrapping an anaeroid sphygmomanometer cuff, inflated to a pressure of $20 \mathrm{mmHg}$, around the lateral aspect of the ankle. The cuff was included in the strapping (Figure 1).

Pressure variations were recorded:

While lying supine every day for the five days of the study, including the day of strapping

While standing on one day only

In the different walking phases (heel strike, full foot and heel off $)^{12}$ on day one only.

The cuffs had been tested for air tightness by inflating them at different pressures, and keeping them still for five days. The maximum difference was less than five per cent. The subjects were asked to abstain from any physical activity, and to spend as much time as possible sitting at home with the leg elevated for the four days following each taping procedure. The results were analysed using the chi-square test. Significance level was set at $P<0.05$.

\section{Results}

In four cases, all with tapes 1 and 2 , the cuff slid along the ankle. The investigators were not able to measure accurately the compression pressure after the third day. In three cases, with the adhesive tapes, cutaneous hypersensitivity reaction developed, evident only when the tapes were removed. Results are shown in Table 1 and in Figure 2.

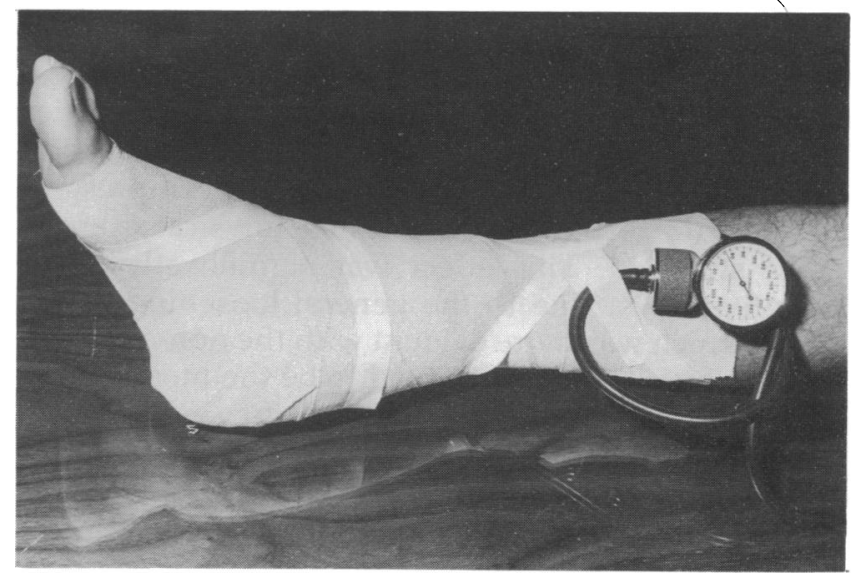

Figure 1. The experimental model 
Table 1. Pressure variations recorded during the five day study

\begin{tabular}{lccc}
\hline & Transelast & Thuasne & Adhesive tapes \\
\hline At rest & $38.3 \pm 3.3$ & $58.6 \pm 4.1$ & $55.9 \pm 3.8$ \\
Standing & $41.2 \pm 2.9$ & $65.4 \pm 2.5$ & $80.0 \pm 6.1$ \\
Heel strike & $44.1 \pm 2.8$ & $70.4 \pm 3.2$ & $85.7 \pm 5.6$ \\
Flat foot & $46.1 \pm 2.5$ & $74.5 \pm 4.2$ & $90.8 \pm 5.4$ \\
Heel off & $49.2 \pm 3.0$ & $77.4 \pm 3.7$ & $94.7 \pm 4.9$ \\
\hline
\end{tabular}

The adhesive tape figures given are the average of the three elastic adhesive tapes used. All values are in $\mathrm{mmHg}$

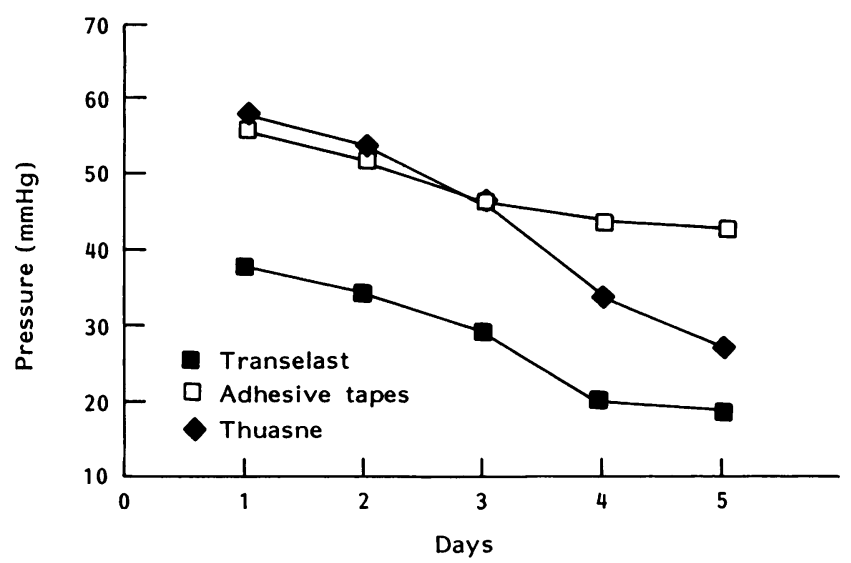

Figure 2. Pressure profile of the tapes

Transelast exerts the least pressure at all stages. There were no statistically significant differences among the three operators with any of the five tapes.

\section{Discussion}

Several methods have been advocated for treating ${ }^{13-15}$ and preventing ${ }^{4,16,17}$ first and second degree inversion injuries of the ankle. Some studies have shown that taping is indeed effective ${ }^{15,16}$ while other investigators obtained better results with ankle stabilizers ${ }^{17} 18$.

In the present study, great care was taken to standardize taping technique, but the use of different materials could account for non-detectable and nonquantifiable differences in handling. Wide variability in compression was shown by the different tapes, with the elastic adhesive tapes giving the highest compression. This could be linked with the intrinsic properties of the tapes, which should prevent fluid extravasation from the interstitial compartment. The compressive effect could be lost by performing physical exercise while strapped. This effect was significantly lower after five days, due to the general loosening of the tapes, which was more evident with the non-adhesive tapes. Non-elastic tape proved to be the most restrictive $^{19}$. At the end of a simulated training session, even
After the third day, a non-adhesive strapping should be renewed. Some effective compression is still exerted by the elastic adhesive tapes after five days (Figure 2). This should be taken into account when planning a therapeutic programme for a sprained ankle.

The three operators had been trained together and were routinely working together. If more than one operator is performing ankle taping in a clinical and/or research environment, it is important that they use a technique as similar as possible to each other, in order to be able to maximize and compare the results, and to give reliable prognostic indications.

\section{References}

1 Balduini, F.C., Vegso, J.J., Torg, J.S. and Torg, E. Management and rehabilitation of ligamentous injuries to the ankle Sports Med 1987, 4, 364-380

2 Kulund, D.N. 'The injured athlete' J.B. Lippincott Company, 1988, Philadelphia

3 Quigley, T.B., Cox, J. and Murphy, J. Protective wrapping for ankle IAMA 1946, 132, 924

4 Ekstrand, J., Gillquist, J. and Liljedahl, S.O. Prevention of soccer injuries. Supervision by doctor and physiotherapist Am J Sports Med 1983, 11, 116-120

5 Thorndyke, A. Frequency and nature of sports injuries Am J Surg 1959, 98, 316-324

6 Larsen, E. Taping the ankle for chronic instability Acta Orthop Scand 1984, 55, 551-553

7 Vaes, P., De Boeck, H., Handelberg, F. and Opdecam, $P$. Comparative radiologic study of the influence of ankle joint bandages on ankle stability Am J Sports Med 1985, 13, 46-50

8 Sperryn, P.N. 'Sport and medicine' Butterworths, 1983, London

9 Pope, M.H., Renstrom, P., Donnermeyer, D. and Morgenstern, S. A comparison of ankle taping methods Med Sci Sports Exerc 1987, 19, 143-147

10 Bonci, C.M. Adhesive strapping techniques Clin Sports Med 1982, 1, 99-116

11 Cerney, J.V. 'Complete book of athletic taping techniques' Parker Publishing Co, 1972, West Nyack

12 Williams, M. and Lissner, $\mathrm{H}$. 'Biomechanics of human motion' W.B. Saunders, 1977, London

13 Cox, J.S. Surgical and non-surgical treatment of acute ankle sprains. Clin Orthop 1985, 198, 118-126

14 Korkala , O., Rusamen, M., Jokipii, P., Kitomaa, J. and Arikaimen, V. A prospective study of the treatment of severe tears of the lateral ligaments of the ankle. Int Orthop 1987, 11, 13-17

16 Myburgh, K.H., Vaughan, C.L. and Isaacs, S.K. The effects of ankle guards and taping on joint motion before, during and after a squash match Am J Sports Med 1984, 12, 441-446

17 Tropp, H., Asling, C. and Gillquist, J. Prevention of ankle sprains Am J Sports Med 1985, 13, 259-262

18 Rovere, G.D., Clarke, T.J., Yates, C.S. and Burley, K. Retrospective comparison of taping and ankle stabilizers in preventing ankle injuries Am J Sports Med 1988, 16, 228-233

19 MacCartee, C.C. Taping treatment of severe inversion sprains of the ankle. Early return to functional activities Am J Sports Med 1977, 5, 246-247 